\title{
Oxycodone treatment for pain in herpes zoster
}

Dworkin and colleagues have shown that oxycodone is an effective treatment for acute pain in patients with herpes zoster. These patients typically experience acute pain, and some develop chronic painpostherpetic neuralgia (PHN)-long after other symptoms have disappeared.

Dworkin explains, "current treatment of herpes zoster with antiviral agents reduces the severity of patients' acute pain and there is also some evidence that it reduces the likelihood of developing PHN and its duration," but, he adds, "many patients still have severe acute pain and a substantial number develop prolonged pain despite antiviral therapy."

Dworkin and colleagues enrolled 87 patients with herpes zoster (age $\geq 50$ years). Patients were treated with famciclovir, an antiviral agent, for 7 days in combination with either controlled-release oxycodone (an opioid analgesic used for moderateto-severe pain), gabapentin (used for the management of PHN), or placebo, each taken for 28 days.

The authors observed a substantial reduction in the severity of acute pain in oxycodone-treated patients. No such reduction in pain was observed in the placebo and gabapentin groups. All treatments were generally well tolerated.

Commenting on the implications of these results, Dworkin says, "it would be important to determine whether treatment of acute pain with this [oxycodone] medication (or perhaps another opioid analgesic) in combination with an antiviral agent would further reduce the risk of PHN compared to treatment with only an antiviral agent."

\section{Lisa Richards}

Original article Dworkin, R. H. et al. A randomized, placebocontrolled trial of oxycodone and of gabapentin for acute pain in herpes zoster. Pain 142, 175-176 (2009). 